\title{
Diversidade e educação especial em diálogos: reflexões sobre os discursos da inclusão
}

\author{
Antônio Carlos do Nascimento Osório* \\ Tatiana Calheiros Lapas Leão**
}

Resumo

Este artigo trata de questões referentes à produção dos discursos sobre a inclusão, tendo como ponto de apoio aqueles direcionados aos alunos da educação especial no processo de escolarização, nas escolas ditas comuns. O aporte teórico e metodológico tem como base os referenciais de Michel Foucault e suas possibilidades epistemológicas de compreensões, enquanto uma problematização cercada por um imaginário social sobre as possibilidades de uma inclusão. Para Foucault (1975), a valorização da diversidade se imbrica na formação do conceito de anormalidade, com os princípios de verdade e justiça, no grotesco exercício da mecânica do poder, saber em vista a um sujeito dito diferente. Estabeleceu-se como objetivo, nesta discussão, uma reflexão de alguns arquivos que antecederam as orientações dos subsídios do documento elaborado como Política Nacional de Educação Especial. Nessa reflexão, sob a perspectiva da inclusão, são demonstrados suas possibilidades e seus limites de transgressão, deixando evidente que isto não se limita aos aspectos relacionados às práticas pedagógicas e sim, às práticas sociais demarcadas por um arsenal de preconceitos. Os resultados revelaram que, no momento atual, os discursos produzidos sobre a inclusão escolar, contidos nesses arquivos, trazem o exame como estratégia de aglutinação, permitindo um melhor controle das diferenças e que as instituições escolares, embora não venham dando conta nem daqueles alunos ditos normais, são responsáveis por essa correção social. Tais condições geram uma variedade de diferentes desafios à estrutura escolar, fruto de distorções acumuladas pelo desvio de seus propósitos, como sendo campo de conflitos e espaço para reforço das diferenças sociais.

Palavras-chave: Diversidade; Educação Especial; Discursos e Inclusão.

\footnotetext{
* Professor Doutor do Programa de Pós-Graduação em Educação da Universidade Federal de Mato Grosso do Sul. Campo Grande, Mato Grosso do Sul, Brasil.

** Doutora em Educação pelo Programa de Pós-Graduação em Educação do Centro de Ciências Humanas e Sociais da Universidade Federal de Mato Grosso do Sul (PPGEdu/CCHS/UFMS). Campo Grande, Mato Grosso do Sul, Brasil.
} 


\title{
Diversity and special education in dialogues: reflections about the inclusion discourse
}

\begin{abstract}
This article addresses issues related to production of discourses on inclusion of special education students within the schooling process in regular schools. The theoretical and methodological framework is based on references of Michel Foucault and his epistemological possibilities of understanding as a problematization surrounded by a social issue about inclusion possibilities. For Foucault (1975), valuing diversity is enmeshed in the formation of the concept of abnormality, with the principles of truth and justice, in the grotesque exercise of the mechanics of power, knowledge concerning a subject seen as different. The objective in this discussion is to do a reflection on some files which preceded the orientation of subsidies of the document produced as National Policy on Special Education. In this reflection, under the inclusion perspective, their possibilities and limits of transgression are demonstrated together, making it clear that this is not limited to the aspects relating to teaching practices and, but to social practices marked by an arsenal of prejudices. The results revealed that, nowadays, the discourse on school inclusion in these files bring the exam as a strategy for agglutination, allowing a better control of the differences and that the schools that have not been able to care for those students considered normal are now responsible for this social correction. Such conditions create a variety of different challenges to school structure, results from accumulated distortions by the deviation of these purposes, as field of conflicts and strengthening of social differences.
\end{abstract}

Keywords: Diversity; Special Education; Discourse and Inclusion.

Nos últimos anos, temos desenvolvido estudos a partir dos referenciais teóricos e metodológicos de Michel Foucault e projetos ${ }^{1}$ de pesquisas, servindose de seus resultados como suporte para elaboração de relatórios de monografias, dissertações e teses, aglutinando outras linhas de pesquisas e programas de pósgraduação. Da base epistemológica enunciada, as reflexões ganham corpo pelas dinâmicas de poder, saber e sujeito em suas relações institucionais dimensionadas pelas práticas culturais e sociais, como produtoras de discursos, sendo estes geradores de acontecimentos e, como foco, neste artigo, a diversidade e a educação especial.

A partir dos resultados das pesquisas, fomos nos aproximando, gradativamente, de outros interesses e problematizações do que vinha sendo observado, gerando outras questões - caminhos para a investigação - e outras percepções dos mesmos fatos, que, a priori, por seus resultados, demonstravam, na época, indícios de uma consolidação. Entretanto, o tempo comprovou o contrário, exigindo, assim, a necessidade de novos aprofundamentos em compreensões de uma forma mais pontual, essencialmente em relação aos fundamentos. 
Dessa forma, direcionou-se a uma concentração das fontes utilizadas, entre as quais, selecionaram-se alguns arquivos que foram analisados na época dos estudos. Eles indicaram outros elementos, a partir de outras informações, que vêm caracterizando a educação especial, pelas condições históricas, e a condicionam pelas práticas culturais, como uma modalidade de ensino destinada a um grupo social em risco composto de filhos e filhas da diversidade social.

O que se busca, neste momento, é compreender a emergência desses discursos marcados por dimensões que levam alunos à condição de sujeitados a sua própria existência. São como objeto da história, que, ao mesmo tempo, os reconhece, os valoriza e os exclui, por suas características pessoais, na condição de uma anomalia, cuja diferença é compreendida como risco e atentado ao pudor da ordem vigente - a própria segurança da sociedade.

Nessa rede de relações, que não se limita ao anunciado até aqui, permite afirmar que os mecanismos latentes na organização da sociedade se instituem exatamente pelos perigos e atentados que poderão se submeter pelas anomalias produzidas pelas diferenças. Acima de tudo, marcam desvios que, necessariamente, poderão ser de condutas ou de aparências, pela suspeita, e não sendo preciso, nesse caso, uma comprovação, pois as condenações já estão estabelecidas em penalidades, em uma prisão sem grades com os limites no próprio corpo.

Com isso, os discursos de inclusão, reforçados na última década, só podem ser analisados como um paradoxo, não se autoexplicam e se alinham a outras redes de discursos voltados para mudanças, superação das diferenças e dos conflitos, visando à outra ordem social. Passam a ser um campo minado, na medida em que as dimensões desses embates se localizam a partir das lutas de raça, associados ao gênero, à cor, ao uso do corpo como um todo e projetados às condições institucionais. Estas o reforçam, pelo conjunto ou isolados, das diferenças, provocando um défice social, produzido pelas práticas culturais.

Foucault (1966) explica que há uma ordem na disposição das coisas, para o saber, e que nada mais é do que o discurso de cada época, tendo um valor, um significado, por isso emerge e passa a ocupar um espaço de verdade. Abrem-se, assim, outras brechas, emergindo outros discursos, outras verdades, porém, com outras tecnologias de poder. Com isso, entende-se que os discursos apenas são possíveis pelas práticas sociais presentes na sociedade, ganhando uma especificidade por justificativas de todas as ordens em cada instituição.

No caso da diversidade, a possibilidade do paradoxo da inclusão passou a significar uma ruptura, um avanço em relação aos movimentos adotados até então. Especificamente na educação especial o princípio é de integração. Este pode ser traduzido por um "ajustamento" da pessoa com deficiência ao processo de escolarização, naquilo que alguns denominam de escolas comuns, diante de um modelo clínico (deficiência na doença pela doença), por isso, ao atendimento, à assistência, ao individual, envolvendo aspectos mais de ordem emotiva do que de 
potencialidades para aprendizagem, centrada em um sujeito, com possibilidades de aquisição do conhecimento numa relação do diferente com o dito normal.

Diante disso, o paradoxo da inclusão emerge pela possível exaustão do movimento integracionista, sendo "substituído" por discursos voltados à igualdade e aos mesmos direitos e tendo em seu contraponto a exclusão. Sua operacionalidade aponta para uma reestruturação do sistema educacional, tendo como foco o ensino regular e o propósito de fazer com que a instituição escolar se torne inclusiva. Para isso, é necessário que ela se torne um espaço democrático e competente para trabalhar com todos os educandos, sem distinção de raça, classe, gênero ou características pessoais, baseando-se no princípio de que a diversidade deve não somente ser aceita como, também, desejada demarcando um discurso ideológico (BRASIL, 1996, p. 26).

Esses discursos marcados por justiça permitem localizar as possibilidades de inclusão, por meio da escolarização, reforçando os interesses e domínios das diferentes dinâmicas seletivas, de construção e desconstrução, de possibilidades e limites, de desejos, angústias, desprazeres e frustrações. Isto extrapola a redução de que ela ocorre em espaço exclusivo, privilegiado para aprender ou ensinar, mas de reforçar, de diferentes formas, a seletividade social presente em outras relações institucionais.

Diante disso, a educação especial passa a ser compreendida em seus extremos, pelas suas bordas. Marcada, como oposto ao movimento da integração, até então, embora perverso, pois exigia do aluno seu enquadramento no processo de escolarização, nem que fosse a espaços isolados nas próprias instituições escolares, centrado em um sujeito pelas suas limitações. Todavia, deixava evidente a possibilidade de aprendizagem, pelas condições de cada aluno, embora em sua maioria não ocorresse, sendo apenas um depósito.

Contraditoriamente, o movimento da inclusão, mais de cunho ideológico do que de respeito à própria diversidade, transfere para a estrutura do sistema educacional (leis, programas, instituição escolar) a responsabilidade de aceitar a matrícula desses alunos (acesso) em classes comuns e determina uma radical transformação de suas práticas pedagógicas, no sentido de respeitar as diferenças, embora elas sejam uma consequência das práticas culturais exercidas.

Ora, se a produção da diversidade, institucionalmente, ocorre por esse espaço pedagógico, este determina e reforça as características de cada um, seja pelas limitações no processo de aprendizagem dos alunos ou por seus comportamentos. Ele os classifica em todas as etapas pedagógicas, muitas vezes sem nenhuma competência profissional, produzindo deficiências e um arsenal de outros delitos, respaldados pela própria sociedade - responsável pela uniformização de atitudes.

Isso nos remete, então, a delimitar a educação especial, para nossas análises, a um espaço criado pela sociedade, referendado por leis, movimentos sociais, programas, exigindo compreendê-lo pela objetividade de suas relações. Esta só poderá 
ser observada por estratégias e mecanismos, adotados naquilo que denominamos como síntese dessa compreensão - a escolarização, legitimidade seletiva fundada nos interesses da própria sociedade, concebida no momento atual como constitutiva de um direito de todos - políticas de inclusão escolar.

Nesse sentido, a inclusão deve ser entendida pelos eventos que circunscrevem o processo de existência coletiva e individual, a partir das práticas culturais, produtoras de verdades instituídas, pelas tentativas de normalização e regularização da diferença, buscando, por um arsenal de mecanismos, a construção ou adequação de estratégias de controle, podendo ser permanentes ou provisórios. Isso se dissolve na cumplicidade entre o Estado, a família, a religião e os demais espaços institucionais, pelo próprio capital, essencialmente pelas diferenças presentes na sociedade, produzidas pelo preconceito, que circula e se aloja em cada sujeito como uma condição oriunda das diferenças no coletivo, reguladas em seus limites.

Essa relação ocorre em redes tecidas em uma composição de diferentes fios. Isto torna, no caso, a escolarização em uma prática social, desde seu surgimento, explicando sua legitimidade seletiva, como um poder atribuído e referendado, pela própria sociedade, embora em um contraponto das expectativas geradas, por essa mesma sociedade, produzindo um conjunto de possibilidades calcadas em suas contradições, que visam à exclusão negando as condições históricas do próprio conhecimento na vida de cada um.

Essa sua legitimação e seu reconhecimento criam vácuos, pelos conflitos e desajustes a partir de sua própria organização, costurado em micropoderes, pelos fios dos diagnósticos, conteúdos, objetivos, avaliações, sempre pelo princípio de separação, pelo ordenamento legal de regras e normas produtoras não tão peculiares, traduzidas como práticas pedagógicas específicas.

Diagnosticar a atualidade pela história exige um sutil cruzamento de uma fina erudição, de um engajamento pessoal e de um trabalho sobre o acontecimento. Foucault (1975) diria que a valorização da diversidade se imbrica na formação do conceito de anormalidade, com o princípio da convicção íntima, das circunstâncias atenuantes, das relações possíveis entre verdade e justiça, no grotesco exercício da mecânica do poder e saber, visando o sujeito.

Os anormais (filhos da diversidade), um grande domínio de ingerência torna-se necessário à intervenção do Estado, em sua "defesa", em seu apaziguamento, não necessariamente promovendo uma transgressão da precarização contida nessas relações de seletividades presentes e, nem nas características do indivíduo, propiciando, na medida do possível, preocupações e novos discursos, nem que sejam só pela mídia.

Ao pinçar a constituição da família, com diferentes formas de estruturação celular, uma questão permanece e sobrevive à história. Encarrega-se do corpo e da vida de sua prole, por diferentes concessões impostas pela necessidade de sobrevivência. 
Em se tratando da escolarização, as condições propiciadas pelo Estado são marcadas pela precariedade do acesso ao saber, produzindo analfabetos funcionais, sem considerar outros aspectos. Tornam-se aceitáveis à família, a partir do momento em que ela não mais se responsabiliza pela "educação", "saúde" e "alimentação" de sua prole, e cabe ao Estado, essa normalização e, ao mesmo tempo, é o que se encontra disponível como direito de todos.

Ao retornar à família, destaca-se que ela está conectada, como qualquer indivíduo, ao novo modelo de sistema de controle e poder. Explica-se assim a infância, fruto de uma condição histórica da generalização do saber e do poder psiquiátrico, pois, na atualidade, tem em vista a inclusão. A psiquiatrização da infantilidade e a constituição de uma ciência das condutas normais e anormais situam essa etapa da vida como um problema mais de ordem social do que familiar, pelos reduzidos espaços que a própria família tem em atuar junto a sua prole. Isso redimensionou as construções teóricas da psiquiatria da segunda metade do século XIX, associadas a outros campos, como psiquiatria e racismo, psiquiatria e defesa social, entre outros.

Com isso, o importante passa a ser a vaga nessa instituição e não os processos que ela constrói ou destrói, se a criança aprende ou não, o que e como ela aprende. A garantia passa a ser o maior número de horas que ali possa ser guardada, independente das condições em que isso ocorrera e as violências que possa sofrer. $\mathrm{O}$ estranho é que, nesse espaço, não se discute, mas se têm evidências das condições em que ocorrem as produções pedagógicas, o comprometimento ao direito à educação e também onde se quer matricular os alunos da educação especial.

Ao dimensionar os discursos sobre a inclusão, requer ter clareza, que ele surge de relações distintas e até antagônicas, e, por conta disso, traz, em si, uma composição formatada por contradições, visando à universalidade de direitos pelas diferenças. Ao aproximar de suas raízes, merece destacar que a expressão inclusão contém a qualidade de existir em si a sua própria negação (exclusão) e uma não existe sem a outra.

Como discursos emergentes, esses direitos fornecem estrategicamente pautas oriundas das fontes de políticas, leis, planos e programas governamentais, movimentos sociais e sindicais, independentes de agrupamento partidário, e ganham corpo, margeados por valores de cunho cultural e social, calcados pela indignação (desajuste) de um determinado grupo ou indivíduo e se localizam no campo emocional, essencialmente voltado à assistência, não garantindo a mudança do revelado, mas sim a compaixão ou indignação.

Isso exige explorar um pouco mais os discursos sobre inclusão, a partir de sua condição de problematização multifacetada, por conta de se objetivar em redes de relações, provenientes de diferentes origens. Tem como marco geral o rápido e desordenado processo de urbanização, mobilidade profissional, desigualdades de renda, o acesso aos bens e serviços, mas, essencialmente, o que nos difere. É um processo em curso que atinge cada vez mais todas as camadas sociais - o preconceito. 
Com isso, cabe explorar um pouco as dinâmicas da exclusão, pois elas sempre são sutis ou até silenciadas, outras referendadas pela própria sociedade, até uma distorção, como é o caso da instituição escolar.

Tanto uma como a outra, embora em pontos extremos, estão presentes na vida de cada um, determinando as condições existenciais e a própria constituição de si. Esses mecanismos, historicamente têm sido regrados pela segregação e asilo, revigorados pelas diferenças e por interesses pontuais, frutos das práticas culturais mais perversas possíveis.

A proposta passa a ser, a partir deste momento, uma reflexão do conjunto de saberes produzido sobre a inclusão relacionada à educação especial, tomando alguns aparatos reguladores - arquivos, nos quais deixam evidentes que, antes de se pensar a educação especial, é necessário compreender que a educação se insere em um projeto social em longo prazo, em políticas de Estado e não deriva de um projeto partidário conduzido pelo poder prévio personalizado, marcado por discursos de inclusão.

Por outro lado, as condições históricas do momento e das atribuições sociais redirecionam a educação especial a uma exaustão de sua compreensão de quaisquer procedimentos, em substituição ao atendimento e assistência propagada durante várias décadas, base de sua consolidação. É necessário pôr em pauta a terminalidade de escolarização de seus alunos, pelas suas condições de aprendizagem e não por um protótipo de aluno que nem os ditos normais cumpriram e não asilá-los por décadas, por não ter atingido aquilo que valorizam como conhecimento.

Essa rede, por assim afirmar, ocorre por conta que muitos comentam sobre determinados direitos, os quais nunca leram, só ouviram falar, menos ainda viram ser operacionalizados. Mas tomam posições, acusando o seu não cumprimento ou defendendo, ignoram a prática cultural sobre eles, marcada por discriminações.

Em 2006, começaram a circular alguns discursos sobre a definição de uma política nacional de educação especial. Tinha como perspectiva a inclusão escolar, adotando como dispositivo um conjunto de orientações normativas e uma adequação da instituição, na medida do possível, sobre suas práticas educativas. Isto para recuperar os aspectos da escolaridade formal, que talvez nunca tenham saído de utopia, contida em relatórios de estudos e nos próprios regulamentos, desde a chegada dos portugueses ao Brasil.

Instituída pela periferia do sistema de ensino, a educação especial tem suas origens em modelos não tradicionais, ignorando a escolarização e enfatizando o atendimento (assistência), proposto pelo modelo de saúde (psiquiátrico) e referendado por um discurso carregado por elementos de uma prática pedagógica. Porém, em seus exercícios, se explicitam mais pelas práticas culturais em relação à deficiência. 
Sobre as possibilidades dos processos de exclusão e inclusão dos indivíduos, Foucault (2005) analisa os procedimentos tomados pelo poder público na Idade Média em relação aos leprosos e aos doentes da peste. Os primeiros eram os considerados excluídos e os segundos, os incluídos. Para o autor, a exclusão é o poder negativo, punitivo, é aquele poder que, por excelência, marginaliza, e a inclusão é o poder que inclui para governar, por esquemas diferentes.

Esses processos, acompanhados de mecanismos e estratégias, deramse pela criação de espaços sociais que aos poucos foram se institucionalizando por necessidades de segurança coletiva, como o asilo, a casa psiquiátrica, a penitenciária, a casa de correção, as creches, o estabelecimento de técnicas da educação vigiada (regimentos, currículo, planos de ensino, avaliação) da escola e outras entidades (assistência). Sobre isso, enfatiza o autor: "[...] instâncias de controle individual funcional num duplo modo: o da divisão binária e da marcação (louco-não louco; perigoso-inofensivo; normal-anormal)"; e o da "[...] repartição diferencial" (quem é ele; onde deve estar; como identificá-lo e caracterizá-lo; como classificá-lo e como isolá-lo). Continua Foucault (2005, p. 176): “[...] como exercer sobre ele, de maneira individual, uma vigilância constante, etc.". Eis porque os discursos de inclusão surgem e se revigoram pela diversidade.

Mesmo considerando que o modelo de exclusão sempre estará ativo, por conta da estrutura econômica capitalista selvagem, modelo adotado pelo Estado brasileiro, tendo um valor representado por diferentes discursos de inclusão e interesses contidos em todas as instituições (exclusão), Foucault (2005) coloca a sua gradativa substituição pelo modelo da inclusão, nem que seja para reforçar os próprios mecanismos de exclusão.

Com isso, a inclusão concebida na atual conjuntura se encaminha para o controle da população vítima da peste na Europa do século XVII pelo exame das possibilidades, para produzir melhor os efeitos e as novas tecnologias de exclusão (FOUCAULT, 2005). Não há mais espaço para governar pela exclusão, sem respeitar a diversidade. É um modelo já saturado e perigoso para a própria sociedade. Abrese na sociedade as brechas pela instituição escolar, pela saúde, pela casa própria e assim adentrem os "anormais" ao circuito dos mesmos direitos referidos por Foucault (2005). Passa a ser necessário incluir e dar acesso para melhor examinar, conhecer, controlar, normalizar e regularizar, e endividar assim se compreende o sentido das políticas de inclusão.

Tal análise passa a ser feita na direção ,não só do mundo das ideias, como também do melhor ou pior, na direção dos comportamentos, das lutas, dos conflitos, das decisões e das táticas. Isso nos remete, então, a entender, na medida do possível, os discursos pelos quais as pessoas são pertencentes à condição de diversidade, instigando perguntas e olhares entre as pessoas "ditas" normais, respondem umas às outras, não informam o que pensam, apenas os "usam" e dizem o que fazer, mas não sabem como, pois não estão preparadas emocionalmente. 
São as estratégias dos discursos de uns em relação aos outros; são táticas empregadas para chegar à verdade, para o enfrentamento, para um possível domínio. Com isso, o objetivo passa a ser o estudo do arquivo, da existência acumulada dos discursos reguladores da diferença que incluem e excluem a escolarização como um dos centros de reflexão, com foco na educação especial.

Foucault (2005) chama esse procedimento de arqueologia, como a análise do discurso em sua modalidade de arquivo - a inclusão, os jogos das suas regras que, em uma prática cultural, determina o seu aparecimento e o seu desaparecimento, sua permanência e seu esgotamento, sua existência contraditória perante os acontecimentos. São essas regras, postas em ação por práticas sociais em um determinado momento, que explicam ou não que tal fato é verdadeiro ou falso, porque ele também é fruto de outras relações de poderes e saberes, demarcados por interesses, muitas vezes pessoais ou de grupo.

Porém, sabe-se que "[...] em uma sociedade como a nossa, conhecemos, é certo, procedimento de exclusão. O mais evidente, o mais familiar também é a interdição [...]" (FOUCAULT, 2000, p. 9), deixando evidente que esta última funciona na privação, neste caso, nos direitos à educação, até previstos, dificilmente cumpridos, como é o caso da escolarização. É uma das estratégias de controles sociais configuradas e readequadas nos diferentes níveis de concessões, marcadas por diferentes discursos, colocando a instituição escolar como um espaço de fracasso, não só pedagógico, mas também social.

Esses elementos contextuais, frutos dessas questões, levam a sociedade, cada vez mais, a ter iniciativas individualizadas, em formatos de "guetos", calcados em procedimentos reativos ou de resistência. Tanto em um caso como em outro, o conflito aflora pelas utopias diversas de interesses ou pretensões e frustrações individuais e coletivas, explicitadas pelas diferentes formas que os atores se relacionam em suas práticas sociais, visando suas sobrevivências, construindo ou destruindo, identidades e ideários coletivos. Assim, refletem concepções de homem e mundo, essencialmente as diferentes formas e níveis de engajamento social, nas relações de estabelecimento de poderes e saberes, de superação de dificuldades.

Ao tomar alguns documentos para analisar a compreensão dos discursos como princípios de inclusão, é importante mencionar que suas origens ocorrem pela "Declaração Universal dos Direitos Humanos" (1948, p. 5), que apresenta em seu preâmbulo considerações em relação à "dignidade inerente a todos e dos seus direitos iguais e inalienáveis", constituindo os fundamentos "da liberdade, da justiça e da paz no mundo". Afirma que o desconhecimento e o desprezo dos direitos do homem, independente de suas condições existenciais, conduziram a atos de barbárie que revoltam a consciência da humanidade.

Nesse discurso, a partir dos direitos humanos, é que se alinhava a inclusão como paradoxo de uma concepção histórico-social, de superação, no sentido de estabelecer espaços democráticos, na mediação entre as relações autoritárias 
presentes e na busca de novos elementos que valorizassem não mais a padronização de atitudes dos indivíduos, mas sim, as suas características como sujeito de suas condições humanas. O sujeito é constituinte e não constituído.

Nesse contexto, as iniciativas públicas e privadas são marcadas por concepções de padrões voltadas à assistência. Isto gera um número significativo de entidades de caráter filantrópico, seja em suas especificidades de atendimento, seja no sentido de garantia de direitos de um grupo específico. Como o caso das pessoas com deficiência, por meio de associações, movimentos sociais, organizações não governamentais, das mais diferentes ordens. Isto em função dos espaços gerados pela omissão do próprio Estado e de suas responsabilidades educativas e sociais, embora preservados e garantidos por ele, nem que sejam para financiar disfunções institucionais dessas instituições.

Isso exige analisar um pouco o papel do Estado brasileiro. Sua intervenção ocorre por meio de estratégias de concessão e em parcerias com essas entidades, tendo o caráter de campanhas emergenciais e pontuais, visando ao recolhimento de recursos financeiros da sociedade, tentando, na medida do possível, um apaziguamento das crises que essas questões geraram historicamente no interior da sociedade.

Pode afirmar-se, então, que independente da "Declaração Universal dos Direitos Humanos" (1948), seus efeitos, no Brasil, no universo social e pedagógico, não se propagaram pois o preconceito se faz presente por diferentes mecanismos sociais, apontando uma guerra constante. Isso pode ser observado também nos marcos regulatórios das Leis de Diretrizes e Bases da Educação Nacional e a Constituição Federal de 1988.

Embora a Lei nº 4.024, de 20 de dezembro de 1961, de Diretrizes e Bases da Educação Nacional (BRASIL, 1961), tenha representado um avanço significativo em busca de princípios orientadores e unificados para o território nacional, ela manteve concepções discriminatórias, de tal maneira que, ao estudante fossem assegurados "igualdade de oportunidades", como critério básico norteador dos estudos (Título I Dos Fins de Educação, em seu art. $1^{\circ}$ e no Título II - Do Direito à Educação). A educação especial continuava às margens da própria organização da educação nacional, sem um processo pedagógico que visasse à escolaridade articulada ao seu público-alvo.

A Lei no 5.692, 11 de agosto de 1971 (BRASIL, 1971), absorve a prática da cultura vigente, eximindo-se também de quaisquer responsabilidades com a educação especial, embora em seu art. $1^{\circ}$ contenha os objetivos, numa perspectiva oposta a esta afirmação: "[...] proporcionar ao educando a formação necessária ao desenvolvimento de suas potencialidades como elemento de auto-realização, qualificação para o trabalho e preparo para o exercício consciente da cidadania", o que não seria para todos, embora o art. 20 garanta: "O ensino de 1ํㅡㅁ grau será obrigatório dos 7 aos 14 anos, cabendo aos Municípios promover, anualmente, o levantamento da população que alcance a idade escolar e proceder à sua chamada para matrícula". Reitera ainda os serviços de assistência educacional que assegurem aos alunos necessitados, condições de eficiência escolar. 
O direito à educação continuava sustado por alternativas, muitas incentivadas pela própria Lei em vigor e pela prática normativa reacionária do Estado, fomentadora dos mesmos princípios das práticas culturais vigentes que, em essência, não eram a educação, mas as possibilidades de outras estratégias de domínios e por outras formas de seleção.

Meados dos anos 1980, a mobilização da sociedade brasileira em torno de reivindicações e direitos sustados, durante o período da ditadura, retomam discussões que se iniciaram nos anos 1960, interrompidos pelo golpe de 1964. Passou-se a defender rupturas das formas de controle centralizado e do disciplinamento, promovido pelo Estado, durante o governo militar. Eram tentativas de radical mudança nos valores e garantias de direitos civis, embora as práticas culturais vigentes nessa década mantivessem o autoritarismo como regra de controle das diferenças, sendo objeto de negociação entre alguns segmentos da sociedade civil e dos militares.

As discussões se alojaram a partir das possibilidades de incorporação na Carta Magna de 1988, das correções das distorções sociais e educacionais acumuladas até então, com ênfase maior, a área de educação infantil e da saúde. Desde modo, ficou garantido em seu Art. 1ำ que: "A República Federativa do Brasil constitui-se em Estado democrático de direito e tem como fundamentos: a cidadania; a dignidade da pessoa humana; os valores sociais do trabalho e da livre iniciativa".

Após quarenta anos, ficavam "garantidos" os princípios contidos na "Declaração Universal dos Direitos Humanos" (1948), fundamentados na promoção do bem de estar social de todos, sem preconceitos de origem, raça, sexo, cor, idade e quaisquer outras formas de discriminação.

Em termos de educação, no Capítulo III - "Da Educação, da Cultura e do Desporto" Seção I - "Da Educação", em seu Art 205, garante como sendo "[...] um direito de todos e dever do Estado e da família" visando o pleno desenvolvimento da pessoa, seu preparo para o exercício da cidadania e sua qualificação para o trabalho. Passa a ser de responsabilidade do Estado a educação e será efetivada mediante a sua garantia. (Emenda Constitucional nº 14, de 1996 ao Art. 208).

Paralelamente, o movimento mundial pelos direitos humanos, é reforçado por meio de um conjunto de dispositivos, entre eles a "Declaração Mundial de Educação para Todos" - "Satisfação das Necessidades Básicas de Aprendizagem" (Conferência Mundial de Educação para Todos -1990) reafirmando: "[...] toda pessoa tem direito à educação [...]", como tentativa de superação da realidade caótica caracterizada naquela década, apesar dos esforços realizados na maioria dos países. O Brasil não participou desta Conferência, anos após se torna signatário da mesma. O princípio que orienta esse movimento foi o da integração.

A atual LDB (Lei 9394/96) tem como princípio do direito universal à educação para todos, além de outras mudanças se comparada às leis anteriores, como a educação infantil (creches e pré-escolas) como primeira etapa da educação 
básica. Em seu Título I, da Educaçao em seu Art. lo "A educação abrange os processos formativos que se desenvolvem na vida familiar, na convivência humana, no trabalho, nas instituições de ensino [...]", além de alterar sua regularização, que nas leis anterior detinham um caráter universal da educação, delimitando-o ao campo da escolarização a ser desenvolvido "[...] predominantemente, por meio do ensino, em instituições próprias". ( $\$ \mathrm{l}^{\mathrm{o}}$, Art. $\left.\mathrm{l}^{\mathrm{o}}\right)$.

Especificamente, no Capítulo V - Da Educação Especial, em seu Art. 58, (\$ $1^{\underline{o}}$ e $\$ 2^{\underline{o}}$ ), define como uma modalidade, oferecida preferencialmente, na rede regular de ensino, para educandos portadores de necessidades especiais, se propondo de quando houver necessidade, para atender as peculiaridades dos alunos, serviços de apoio, na instituição escolar, detalhando que será feito em "[...] classes, escolas ou serviços especializados, sempre que, em função das condições específicas dos alunos, não for possível a sua integração nas classes comuns de ensino regular".

Cabe aos sistemas de ensino garantir aos educandos com necessidades especiais (Art. 59, inciso I) "[...] currículos, métodos, técnicas, recursos educativos e organização específicos, para atender às suas necessidades;" e "II - terminalidade específica para aqueles que não puderem atingir o nível exigido para a conclusão do ensino fundamental, em virtude de suas deficiências, e aceleração para concluir em menor tempo o programa escolar para os superdotados" com vistas "[...] a sua efetiva integração na vida em sociedade [...] (Art. 59, inciso II).

Foucault (1989) chama esse procedimento de pinçar elementos, neste caso, por tentativas de regularização, como essas Leis, de uma arqueologia inicial, que ainda merecem outros aprofundamentos e correlações, em suas modalidades de arquivos, demarcadas pelos discursos - a integração, o jogo das suas regras que, em uma prática cultural com vista a uma inclusão, determinando a sua emergência frente a exaustão dos acontecimentos.

São essas regras, postas em ação pelas práticas culturais em um determinado momento, que explicam ou não que tal fato é verdadeiro ou falso, porque ele também é fruto de outras relações de poderes e saberes, demarcados por interesses, muitas vezes pessoais ou de grupo. Isso nos permite afirmar que a perspectiva de inclusão da forma em que se coloca, se relaciona diretamente ao acesso a matricula no "ensino comum", mas não garante a aprendizagem do aluno, reforçando a expansão de espaços segregados, já conhecidos como "classes de excepcionais" ou "classe especial", agora incluso em 'salas comuns'.

Há graus diferentes dessas possibilidades em cada pessoa, com ou sem deficiência e é preciso reconhecê-las e dar a cada uma delas o tratamento necessário para sua transgressão, cabendo a instituição escolar organizar situações de aprendizagem, a partir das necessidades pessoais (integração) e interesses de seus alunos (inclusão), propiciando a continuidade dos estudos e sua terminalidade. Resistência determinante dos sistemas de ensino em propiciar essas relações inviabilizando qualquer mudança diferenciada das praticadas até então. 
A inclusão depende, acima de tudo, de convicções, compromisso e disposição política com uma transformação social, a partir de atitudes concretas, visando efetivamente a possibilidades de justiça e respeito à diferença de forma individual e coletiva.

Enquanto um paradoxo encontra seus limites nas práticas culturais, por exercer preconceitos de todas as ordens com vista a diferentes formas de seleção. Reafirma-se então que os aparatos regulatórios perdem suas eficácias, enquanto direito, em função das práticas culturais exercidas, que vão à contra-mão de seus postulados e, ao mesmo tempo, não há interesse por parte do Estado em compreender os processos instituídos, a partir das Leis e outros dispositivos. O que importa é garantir o acesso à matrícula. O que ocorre a partir daí é a luta de sobrevivência de cada um, enquanto mecanismos possíveis de resistências de elaboração, de resistências para uma sobrevivência frente aos preconceitos instituídos.

\section{Referências}

BRASIL. Lei № 9.394, de 20 de Dezembro de 1996. Estabelece as Diretrizes e Bases da Educação Nacional.

Emenda Constitucional no 14, de 12 de setembro de 1996. Modifica os arts. 34, 208, 211 e 212 da Constituição Federal e dá nova redação ao art. 60 do ato das disposições constitucionais transitórias. Diário Oficial [da] República Federativa do Brasil, Brasília, 13 set. 1996. p.18109. Disponível em: 〈http://www.planalto.gov.br/ccivil_03/constituicao/Emendas/Emc/emcl4. htm>. Senado, 1988.

Constituição (1988). Constituição da República Federativa do Brasil. Brasília, DF:

. Lei No 5.692, de 11 de Agosto de 1971. Fixa diretrizes e bases para o ensino de $1^{\circ}$ e $2^{\circ}$ graus, e dá outras providências. Diário Oficial [da] República Federativa do Brasil, Brasília, 12 ago. 1971, retificada em 18 ago. 1971. Disponível em: 〈http://www.planalto.gov.br/ccivil_03/Leis/ L5692.htm>.

Lei N. 4.024, de 20 de Dezembro de 1961. Fixa as diretrizes e bases da educação nacional. Diário Oficial [da] República Federativa do Brasil, Brasília, 27 dez. 1961. p. 11429. Disponível em: 〈http://www.planalto.gov.br/ccivil_03/Leis/L4024.htm〉.

DECLARAÇÃO MUNDIAL DE EDUCAÇÃO PARA TODOS: satisfação das necessidades básicas de aprendizagem. Jon Tien, Tailândia: UNICEF, 1990.

DECLARAÇÃO UNIVERSAL DOS DIREITOS HUMANOS. Adotada e proclamada pela resolução 217 A (III), da Assembléia Geral das Nações Unidas em 10 de dezembro de 1948.

FOUACULT, M. Vigiar e punir: nascimento da prisão. Petrópolis: Vozes, 1985.

Microfísica do poder. Ed. 15. Rio de Janeiro: Graal, 2000.

As palavras e as coisas: uma arqueologia das ciências humanas. [trad. Salma Tannus Muchal; tit. Les Mots Et Les Choses de 1966] 8. Ed. São Paulo: Martins Fontes, 1999. 
FOUACULT, M. Nietzsche, Freud e Marx: theatrum phisosoficum. Porto: Gráfica Firmeza. 1975.

\section{Notas}

1 Este projeto envolveu pesquisadores dos paises do Cone Sul (Argentina, Chile, Paraguai e Uruguai) com financiamento da Organização das Nações Unidas para a Educação, a Ciência e a Cultura (UNESCO) (20002005) e o Projeto "Direito à Educação e a Diversidade Social" (2005-2008), com apoio do Programa de Apoio à Educação Especial/Coordenação de Aperfeiçoamento de Pessoal de Nível Superior/Ministério da Educação (PROESP/CAPES/MEC). O primeiro teve seus resultados como suporte para implementação do Programa Direito à Educação" (2002), coordenado pela antiga Secretaria de Educação Especial/MEC e hoje se encontra na Secretaria Educação Continuada, Alfabetização, Diversidade e Inclusão/MEC, e o segundo, seus subsídios foram referência para a Política de Educação Especial na perspectiva da Inclusão Escolar (2008).

\section{Correspondência}

Tatiana Calheiros Lapas Leão - Rua Vinte e seis de agosto, 1918, Bairro Amambaí, CEP: 79005030, Campo Grande, Mato Grosso do Sul, Brasil.

E-mail: antonio.osorio@ufms.br - tatianacalheiros@hotmail.com

Recebido em 20 de março de 2013

Aprovado em 15 de junho de 2013 